\title{
The mechanism of starch content increase in grain of autotetraploid rice (Oryza sativa L.)
}

\author{
P.M. YANG ${ }^{*+}$, X.R. ZHOU*, and Q.C. HUANG ${ }^{* *}$ \\ Henan Institute of Science and Technology, 453003 Xinxiang, Henan, China* \\ Henan Provincial Key Laboratory of Ion Beam Bio-engineering, Zhengzhou University, 450052 Zhengzhou, \\ Henan, China**
}

\begin{abstract}
Net photosynthetic rate $\left(P_{\mathrm{N}}\right)$, photorespiration $\left(P_{\mathrm{R}}\right)$, chlorophyll $(\mathrm{Chl})$ content, Chl fluorescence parameters, starch accumulation, and related key enzyme activities were determined during the grain-filling stage in two autotetraploid lines and corresponding diploid rice lines. The results showed that autotetraploid rice lines had a higher Chl content, $P_{\mathrm{N}}$, electron transport rate, maximum photochemical efficiency of PSII, actual photochemical efficiency of PSII, and lower $P_{\mathrm{R}}$ in leaves than that in corresponding diploid rice lines during the grain-filling stage. It indicated that autotetraploid rice line had a high photosynthetic capacity and high light-utilization efficiency. The activities of ADP-glucose pyrophosphorylase, soluble starch synthase, and starch-branching enzyme in grains of autotetraploid rice lines were higher than those in grains of corresponding diploid rice lines during the grain-filling stage. Therefore, autotetraploid rice lines were more efficient than corresponding diploid rice lines in converting photosynthetic products into starch.
\end{abstract}

Additional key words: 1000-grain mass; breeding; colchicine; photoassimilate; polyploidy.

\section{Introduction}

Polyploidy is widely accepted to play an important role in the evolution and breeding of plant species (Wendel 2000, Rieseberg and Willis 2007). More than 70\% of angiosperms have undergone at least one round of genome duplication during the course of their evolution (Otto and Whitton 2000, Vandepoele et al. 2003, Hegarty and Hiscock 2008). Polyploid plants exist extensively in nature with the advantages of a larger plant size, better quality, strong adaptive ability, and high biomass yield (Birchler et al. 2003, Tu et al. 2007, He et al. 2011, Yang et al. 2014). Some important crops, such as wheat, cotton, and rape, are polyploid, and their yields doubled when their genomes were duplicated (Rieseberg and Willis 2007).

Rice (Oryza sativa L.) is one of the most important crops for feeding more than half population all over the world. The demand for increasing rice production is particularly urgent, because the population of traditional rice-producing countries requires more rice (Swaminathan 2007). Therefore, it is important for increasing rice production to meet the growing demand. In rice grains, starch is the predominant storage substance that accounts for about $80 \%$ of the total dry mass. It has been well documented that rice yield is mainly determined by the starch content (Asaoka et al. 1985, Reddy et al. 1994, Han and Hamaker 2001, Awika 2011). Recent work showed that multiple factors contribute to the formation of starch, including photosynthesis, and enzymes relevant to starch synthesis (Ball et al. 1998, Nakamura et al. 1989, Nakamura and Yuki 1992, Wang et al. 2015). ADPglucose pyrophosphorylase (ADPG-Ppase), soluble starch synthase (SSS), and starch-branching enzyme (SBE) are the key enzymes involved in starch synthesis in the rice grain (James et al. 2003, Jeon et al. 2010). Although extensive studies have been carried out on the photosynthesis and enzymes related to starch synthesis in diploid rice, little is known about the variation in photosynthesis and enzyme activities relevant to starch synthesis when their genomes were duplicated. In the present study, two diploid rice lines and corresponding autotetraploid lines were used to explore the increase mechanism for the starch content in grains of autotetraploid rice lines.

\section{Materials and methods}

Plant materials: Two autotetraploid rice (Oryza sativa L.) lines SP-4X, 630-4X, and corresponding diploid rice lines SP-2X, 630-2X (Yang et al. 2014) were used in our experiment. Two autotetraploid rice lines (SP-4X and 630-4X) were induced by colchicine-doubling from the diploid rice lines (SP-2X and 630-2X) as described by Tu et al. (2007) with some modifications. Young panicles of diploid rice lines at 0.5 to $2-\mathrm{cm}$ long were cut into pieces and

Received 3 October 2018, accepted 11 February 2019.

+Corresponding author; phone: +86-373-3040384, e-mail: yangpengming@126.com, pengmingyang@tom.com

Abbreviations: ADPG-Ppase - ADP-glucose pyrophosphorylase; Chl - chlorophyll; ETR - electron transport rate; $\mathrm{F}_{\mathrm{v}} / \mathrm{F}_{\mathrm{m}}-$ maximum photochemical efficiency of PSII; $P_{\mathrm{N}}-$ net photosynthetic rate; $P_{\mathrm{R}}$ - photorespiration; SBE - starch-branching enzyme; SSS - soluble starch synthase; $\Phi_{\mathrm{PSII}}-$ actual photochemical efficiency of PSII.

Acknowledgements: This study was funded by the National Natural Science of China (31872882). 
cultured in the medium containing Murashige and Skoog (MS) nutrients plus $1 \mathrm{mg}$ (2,4-dichlorophenoxyacetic acid; 2,4-D) $\mathrm{L}^{-1}, 0.2 \mathrm{mg}$ (kinetin) $\mathrm{L}^{-1}$, and $0.2 \mathrm{mg}$ (indole-3-acetic acid) $\mathrm{L}^{-1}$ for callus induction. The induced callus was implanted on a secondary medium containing MS plus $0.4 \mathrm{mg}\left(\right.$ vitamin $\left._{1}\right) \mathrm{L}^{-1}, 2 \mathrm{mg}(2,4-\mathrm{D}) \mathrm{L}^{-1}, 100 \mathrm{mg}($ inositol $) \mathrm{L}^{-1}$, and $25 \mathrm{~g}$ (mannitol) $\mathrm{L}^{-1}$, three times for $20 \mathrm{~d}$. Uniformly light yellow callus tissues with vigorous growth were selected, cut into 2-mm pieces, and grown in the secondary medium plus $500 \mathrm{mg}$ (colchicine) $\mathrm{L}^{-1}$ for $48 \mathrm{~h}$ at $25^{\circ} \mathrm{C}$ in shaking culture. The callus tissues were filtered with a sterile $0.5-\mu \mathrm{m}$ screen, washed with culture fluid to remove residual colchicine, and cultured in the regenerating medium containing MS plus $2 \mathrm{mg}$ (6-benzylaminopurine) $\mathrm{L}^{-1}$, $0.5 \mathrm{mg}$ (kinetin) $\mathrm{L}^{-1}$, and $1 \mathrm{mg}$ (1-naphthaleneacetic acid) $\mathrm{L}^{-1}$ for inducing shoots. Finally, the callus tissue with shoots was transferred to rhizogenic medium containing $0.5 \mathrm{MS}$ plus $1 \mathrm{mg}\left(\right.$ vitamin $\left.\mathrm{B}_{1}\right) \mathrm{L}^{-1}$ and $0.5 \mathrm{mg}$ (3-indolebutyric acid) $\mathrm{L}^{-1}$ for $20 \mathrm{~d}$. Plants with vigorous roots were transplanted to soil and subsequently into the field. Autotetraploids were selected based on cytological verification.

Experimental design: Field experiment was conducted at the experimental farm in Xinxiang Academy Agricultural Science, Xinxiang, China $\left(35^{\circ} 18^{\prime} \mathrm{N}, 113^{\circ} 52^{\prime} \mathrm{E}\right)$. The diploid rice lines and autotetraploid rice lines were grown in 2017 (from May to October) under the same field conditions. The seeds used for tests were first sown in a seedling bed to promote germination and cultivate young seedlings for $30 \mathrm{~d}$, and then the young seedlings were transplanted to a paddy field. Each rice line comprised of 20 rows, and each row was for 40 individuals; the spacing between the rows was $30 \mathrm{~cm}$, and the spacing between individuals in a row was $15 \mathrm{~cm}$. Two hundred grains were sampled at 15, 30, $45 \mathrm{~d}$, respectively, after anthesis from the middle of ears and divided into two groups. One group (100 grains) was frozen in liquid nitrogen and kept at $-80^{\circ} \mathrm{C}$ for enzyme assays. Another group (100 grains), after their enzymes were deactivated at $105^{\circ} \mathrm{C}$ for $30 \mathrm{~min}$, was dried at $80^{\circ} \mathrm{C}$ to constant mass, and then milled, passed through a 100-mesh sieve and kept in desiccator for starch assays.

Chl content: Leaf Chl content was measured following the method of Arnon (1949) and expressed as $\mathrm{mg} \mathrm{g}^{-1}$ (fresh mass, FM). Samples of approximately $0.5 \mathrm{~g}$ were cut from mid-section of fresh flag leaves. Each sample was grinded in $5 \mathrm{~mL}$ of $80 \%$ acetone (with little $\mathrm{CaCO}_{3}$ and quartz sand), and then stored in dark for $5 \mathrm{~min}$. The solution was filtered into $50-\mathrm{mL}$ volumetric flask. The residues were grinded and filtered again in the same manner. Finally, the volumetric flasks were made up to the mark with $50 \mathrm{~mL}$ by $80 \%$ acetone. The absorbance of the extract was estimated at 645 and $663 \mathrm{~nm}$ using $80 \%$ acetone as a blank with a spectrophotometer UV-4802 (Yuanxi Co., Shanghai, China). The Chl content was calculated using the following equations: total $\mathrm{Chl}=\left[20.29\left(\mathrm{~A}_{645}\right)+8.04\right.$ $\left.\left(\mathrm{A}_{663}\right)\right] \times(\mathrm{V} / 1000 \mathrm{M})$, where $\mathrm{V}$ was the volume of the extracted liquid, and $\mathrm{M}$ was the fresh mass of the sample.

$\boldsymbol{P}_{\mathrm{N}}$ and $\boldsymbol{P}_{\mathrm{R}}: P_{\mathrm{N}}$ was measured under the conditions of natural environment (field) on sunny day. We also recorded changes in PFD and temperature in Xiangxiang at this time (Fig. 1). LI6400 portable photosynthesis system (LI-COR Co., USA) was used to measure the $P_{\mathrm{N}}$ of flag leaves at $15,30,45 \mathrm{~d}$, respectively, after anthesis under natural conditions at 07:00, 09:00, 11:00, 13:00, and 15:00 h. $P_{\mathrm{R}}$ was calculated as described by Guan et al. (2004). The $P_{\mathrm{N}}$ was measured at $\mathrm{O}_{2}$ concentration of about $1 \%$ in order to inhibit the $P_{\mathrm{R}}$. This was achieved by mixing nitrogen gas with normal air in a mixing ratio that resulted in about $1 \% \mathrm{O}_{2}$ which was monitored with an oxygen electrode. $P_{\mathrm{R}}$ was estimated by subtracting $P_{\mathrm{N}}$ under normal $\mathrm{O}_{2}$ concentration from that under $2 \% \mathrm{O}_{2}$. Each result shown was the mean of ten replicated treatments.

The Chl fluorescence parameters of flag leaves were measured with a portable Chl fluorometer (Mini-PAM, Heinz Walz GmbH, Effeltrich, Germany). The mean values of leaf electron transport rate (ETR), maximum photochemical efficiency of PSII $\left(\mathrm{F}_{\mathrm{v}} / \mathrm{F}_{\mathrm{m}}\right)$, and actual photochemical efficiency of PSII $\left(\Phi_{\text {PSII }}\right)$ were measured as described by Baker (2008). The mean value of each leaf ETR, $F_{\mathrm{v}} / \mathrm{F}_{\mathrm{m}}$, and $\Phi_{\text {PSII }}$ was determined by measuring ten leaf samples.

Preparation and assay of enzymes: Twenty dehulled rice grains were hand-homogenized at $4{ }^{\circ} \mathrm{C}$ in a mortar and pestle with $5 \mathrm{~mL}$ of extraction buffer containing $100 \mathrm{mmol}$ Tricine-NaOH, pH 7.5, 8 mmol $\mathrm{MgCl}_{2}, 2$ mmol EDTA, $12.5 \%(\mathrm{v} / \mathrm{v})$ glycerol; $1 \%(\mathrm{w} / \mathrm{v})$ PVP-40, and $50 \mathrm{mmol}$ 2-mercaptoethanol. After centrifugation at $10,000 \times g$ for $25 \mathrm{~min}$, the supernatant solution and deposition were

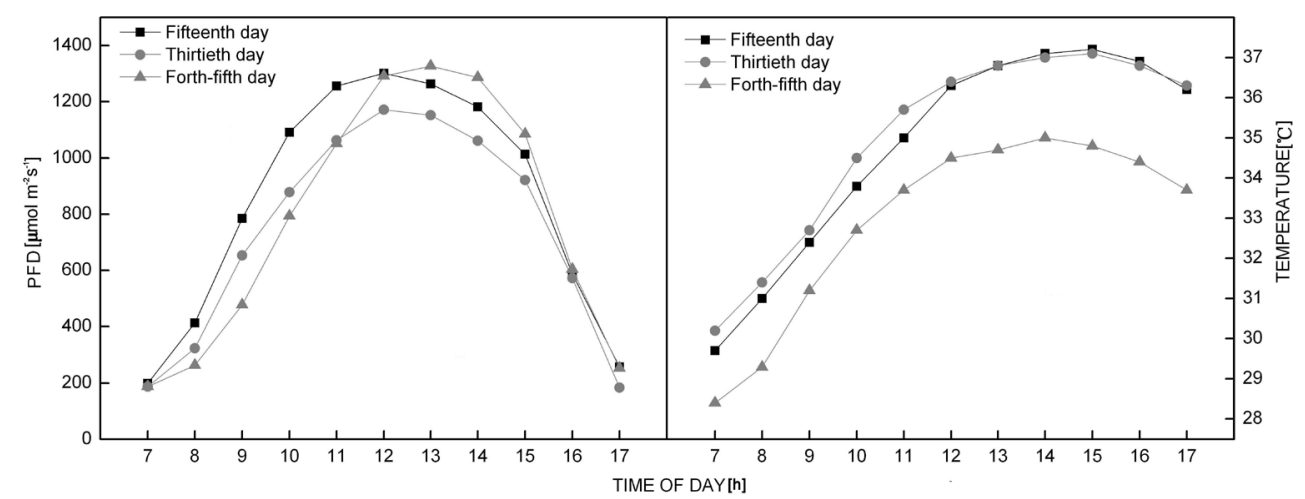

Fig. 1. Diurnal changes of temperature and light intensity during the grainfilling stage of rice. 
collected separately and used as the preparation for individual enzyme analysis. ADP-glucose pyrophosphorylase (ADPG-Ppase, EC 2.7.7.27) and soluble starch synthase (SSS, EC 2.4.1.21) activities were measured as described by Xie et al. (2016). To determine ADP-glucose pyrophosphorylase activity, $20 \mu \mathrm{L}$ of soluble crude enzyme was taken from samples and added into $230 \mu \mathrm{L}$ of reaction liquid consisting of $100 \mathrm{mmol} \mathrm{L}{ }^{-1}$ Hepes- $\mathrm{NaOH}(\mathrm{pH}$ 7.4), $3 \mathrm{mmol} \mathrm{L}{ }^{-1} 3$-PGA, $1.2 \mathrm{mmol} \mathrm{L}{ }^{-1}$ ADPG, $3 \mathrm{mmol}$ $\mathrm{L}^{-1} \mathrm{NaH}_{2} \mathrm{PO}_{4}, 5 \mathrm{mmol} \mathrm{L}{ }^{-1} \mathrm{MgCl}_{2}, 4 \mathrm{mmol} \mathrm{L}{ }^{-1} \mathrm{DTT}, 15$ $\mu \mathrm{L}$ of distilled water. The homogenate was vibrated for 20 min at $30^{\circ} \mathrm{C}$, and the reaction terminated by immersion for $30 \mathrm{~s}$ in $100^{\circ} \mathrm{C}$ boiling water. The resulting supernatant was moved into a 3-mL quartz cuvette to which $450 \mu \mathrm{L}$ of distilled water was added. It was centrifuged at 15,000 $\mathrm{rpm} \mathrm{min}^{-1}$ in the small tube for $10 \mathrm{~min}$ at $2^{\circ} \mathrm{C}$. Then, 15 $\mu \mathrm{L}$ of of $10 \mathrm{mg} \mathrm{mL}^{-1} \mathrm{NADP}$ was added. This was vibrated with film. Absorbance at a wavelength of $340 \mathrm{~nm}$ was measured using an ultraviolet spectrophotometer. This spectral absorbance was re-measured after adding $1 \mu \mathrm{L}$ of PGM and $1 \mu \mathrm{L}$ of G-6-PDH.

To determine soluble starch synthase activity, $40 \mu \mathrm{L}$ of soluble crude enzyme was taken from samples and added to a $140 \mu \mathrm{L}$ of reaction liquid consisting of $50 \mathrm{mmol} \mathrm{L}^{-1}$ Hepes-NaOH (pH 7.4), 15 mmol L ${ }^{-1}$ DTT, $1.6 \mathrm{mmol} \mathrm{L}^{-1}$ ADPG, $20 \mathrm{mg} \mathrm{mL}^{-1}$ glycogen, and $100 \mu \mathrm{L}$ of distilled water. The homogenate was vibrated for $40 \mathrm{~min}$ at $30^{\circ} \mathrm{C}$ and the reaction terminated by immersion for $2 \mathrm{~min}$ in $100^{\circ} \mathrm{C}$ boiling water. Then, $100 \mu \mathrm{L}$ of another reaction liquid (50 mmol L-1 Hepes-NaOH (pH 7.4), $4 \mathrm{mmol} \mathrm{L}^{-1}$ PEP, $200 \mathrm{mmol} \mathrm{L}^{-1} \mathrm{KCl}, 10 \mathrm{mmol} \mathrm{L}^{-1} \mathrm{MgCl}_{2}, 2 \mu \mathrm{L}$ of pyruvate kinase) was added to this solution and continued vibration for $30 \mathrm{~min}$ at $30^{\circ} \mathrm{C}$. This reaction was terminated by immersion for $2 \mathrm{~min}$ in $100^{\circ} \mathrm{C}$ boiling water. Then 100 $\mu \mathrm{L}$ of distilled water was added to this solution, with the resulting supernatant placed in a $3-\mathrm{mL}$ quartz cuvette that was then centrifuged at $15,000 \mathrm{r} \mathrm{min}^{-1}$ for $10 \mathrm{~min}$ at $2^{\circ} \mathrm{C}$, and added into $200 \mu \mathrm{L}$ of a solution containing $50 \mathrm{mmol} \mathrm{L}^{-1}$ Hepes-NaOH (pH 7.4), 20 mmol L ${ }^{-1} \mathrm{MgCl}_{2}, 10 \mathrm{mmol} \mathrm{L}{ }^{-1}$ glucose, $2 \mathrm{mmol} \mathrm{L}^{-1} \mathrm{NADP}$, and $20 \mu \mathrm{L}$ of distilled water. This mixture was then vibrated with film. Absorbance at a wavelength of $340 \mathrm{~nm}$ was measured using an ultraviolet spectrophotometer. This spectral absorbance was remeasured after adding $2 \mu \mathrm{L}$ of G-6-PDH.

Starch-branching enzyme (SBE, EC 2.4.1.18) activity was measured as described by Nakamura et al. (1989).
ADPG-Ppase, SSE, and SSS activities were expressed as $\mu \mathrm{mol} \mathrm{s}{ }^{-1} \mathrm{mg}^{-1}$ (protein). Each result shown was the mean of three replicated treatments.

The starch content in grain of rice was measured using the methods of Fujita et al. (2003).

Statistical analysis: All the data in the present study were expressed as means \pm SE. Significance analysis was performed using $S A S$ software (SAS Institute, Inc., Cary, $\mathrm{NC}$, USA). One-way analysis of variance (ANOVA) method (Duncan's multiple range test) was used to detect the significance $(P<0.05)$.

\section{Results}

Chl content: During the grain-filling stage, the Chl content of autotetraploid rice line was higher than that of corresponding diploid rice line, but the Chl content showed no significant differences between two autotetraploid rice lines and corresponding diploid rice lines in the early stage of grain filling (Fig. 2). The Chl content in flag leaves of all rice lines decreased with the prolongation of grain filling time (Fig. 2), but the Chl content in flag leaves of diploid rice line decreased sharper then those of corresponding autotetraploid rice line. The $\mathrm{Chl}$ content showed significant difference between autotetraploid rice and corresponding diploid rice in the late stage of grain filling (Fig. 2).

$\boldsymbol{P}_{\mathrm{N}}$ and $\boldsymbol{P}_{\mathrm{R}}$ : During the grain-filling stage, the $P_{\mathrm{N}}$ of autotetraploid rice line was higher than that of corresponding diploid rice line, but the difference of $P_{\mathrm{N}}$ between autotetraploid rice line and corresponding diploid rice line was not significant in the early stage of grain filling (Fig. 3). The $P_{\mathrm{N}}$ difference between autotetraploid rice line and corresponding diploid rice line increased with prolongation of grain filling time. The $P_{\mathrm{N}}$ of autotetraploid rice line was significantly higher than that of corresponding diploid rice line in the late stage of grain filling. During grain-filling stage, the $P_{\mathrm{R}}$ of autotetraploid rice line was lower than that of corresponding diploid rice line and the difference of photorespiration between autotetraploid rice line and corresponding diploid rice line was significant in the early stage of grain filling (Fig. 3).

Chl fluorescence parameters: The $F_{\mathrm{v}} / F_{\mathrm{m}}, \Phi_{\text {PSII }}$, and ETR

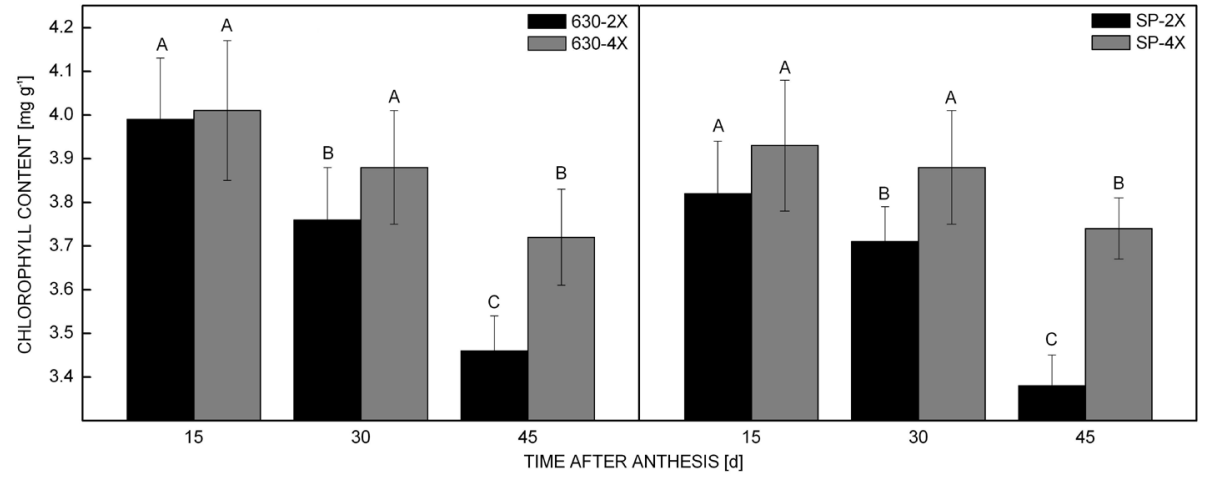

Fig. 2. Chlorophyll content in flag leaves of diploid and autotetraploid rice lines during the grain-filling stage. Error bars show SE, $n=3$. One-way analysis of variance (ANOVA) was used to indentify differences between diploid and corresponding autotetraploid in each time. Values with different letters are significantly different $(P<0.05) .2 \mathrm{X}-$ diploid rice line, $4 \mathrm{X}$ - auto-tetraploid rice line. 


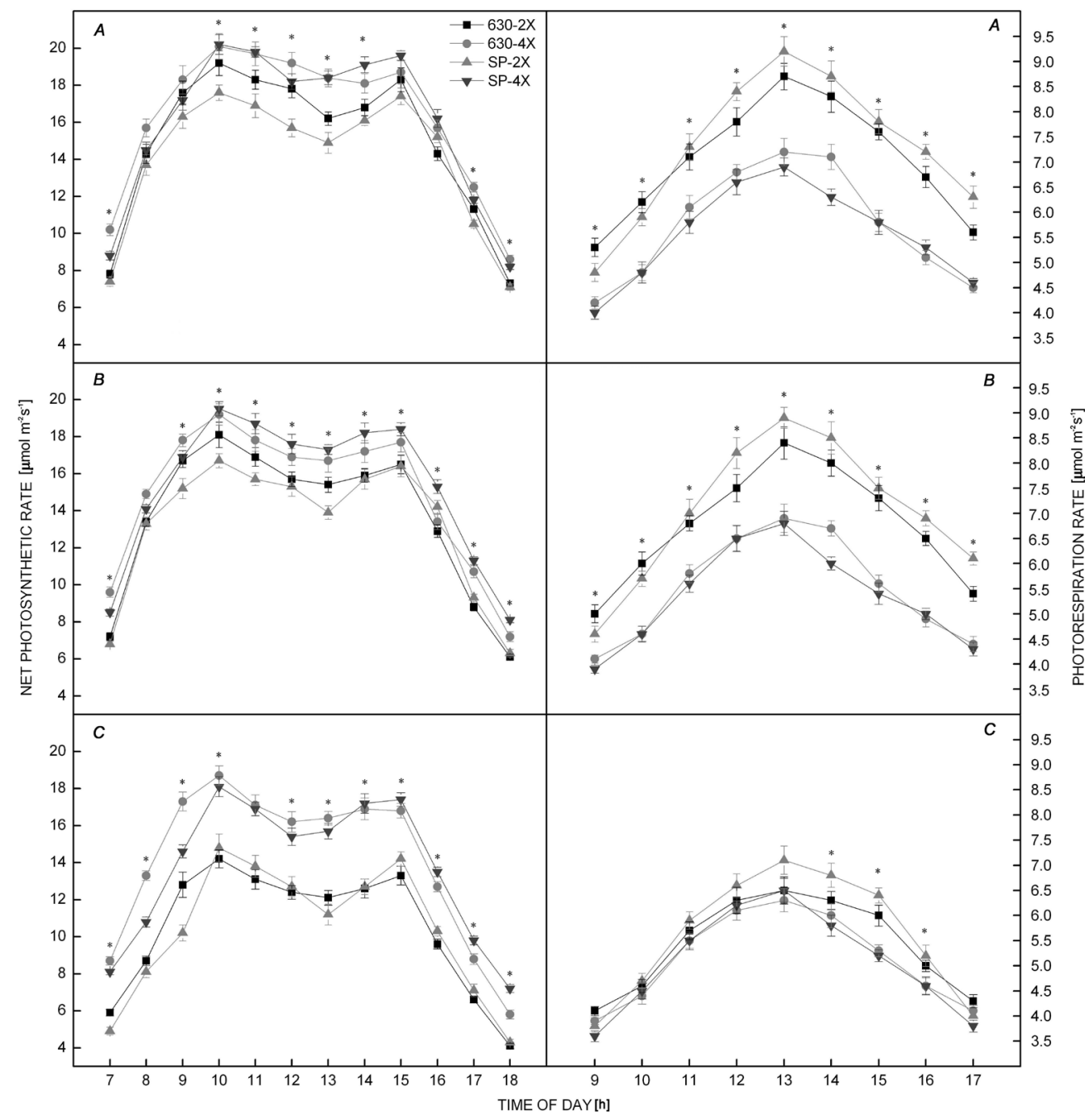

Fig. 3. Changes of net photosynthetic rate $\left(P_{\mathrm{N}}\right)$ and photorespiration $\left(P_{\mathrm{R}}\right)$ in diploid and autotetraploid rice lines during the grainfilling stage: $15 \mathrm{~d}$ after anthesis $(A) ; 30 \mathrm{~d}$ after anthesis $(B)$; and $45 \mathrm{~d}$ after anthesis $(C)$. Error bars show SE, $n=10$. Asterisks indicate significant difference $(P<0.05)$ between two diploid rice lines and corresponding autotetraploid rice lines. $2 \mathrm{X}-$ diploid rice line, $4 \mathrm{X}$ - autotetraploid rice line.

of autotetraploid rice line were higher than those of corresponding diploid rice line during grain-filling stage, and the $\mathrm{F}_{\mathrm{v}} / \mathrm{F}_{\mathrm{m}}, \Phi_{\mathrm{PSII}}$, and ETR showed significant differences between autotetraploid rice line and corresponding diploid rice line during late stage of grain-filling process (Fig. 4). The $\mathrm{F}_{\mathrm{v}} / \mathrm{F}_{\mathrm{m}}, \Phi_{\mathrm{PSII}}$, and ETR of all rice line decreased with the prolongation of grain filling time, but $\mathrm{F}_{\mathrm{v}} / \mathrm{F}_{\mathrm{m}}, \Phi_{\mathrm{PSII}}$ and ETR of diploid rice line decreased sharper then those of corresponding autotetraploid rice line (Fig. 4).

The activities of ADPG-Ppase, SSS, and SBE were significantly higher in autotetraploid rice line than those in corresponding diploid rice line during the grain-filling stage (Fig. 5). The activities of ADPG-Ppase, SSS, and SBE decreased with the prolongation of grain filling time for all rice lines. However, ADPG-Ppase, SSS, and SBE activities in diploid rice line decreased sharper then those in corresponding autotetraploid rice line.
Starch accumulation in filling grains of diploid and autotetraploid rice line: The starch accumulations of different ploidy rice lines are showed in Fig. 6. Starch content increased with prolongation of grain filling time for all rice lines. However, the starch content in autotetraploid rice line increased sharper then those in corresponding diploid rice line, and the starch content in autotetraploid rice line was significantly higher than that in corresponding diploid rice line in maturity. Chromosome doubling had a considerable effect on the starch content in rice grains.

\section{Discussion}

Crop starch depends on the capacity of source tissues (especially flag leaves) to produce photoassimilates during the grain-filling process, as well as on the ability of sink tissues to convert this photoassimilates into starch(Reynolds et al. 2012, Tuncel and Okita 2013). Theoretically, crop starch can be increased by promoting photosynthesis 


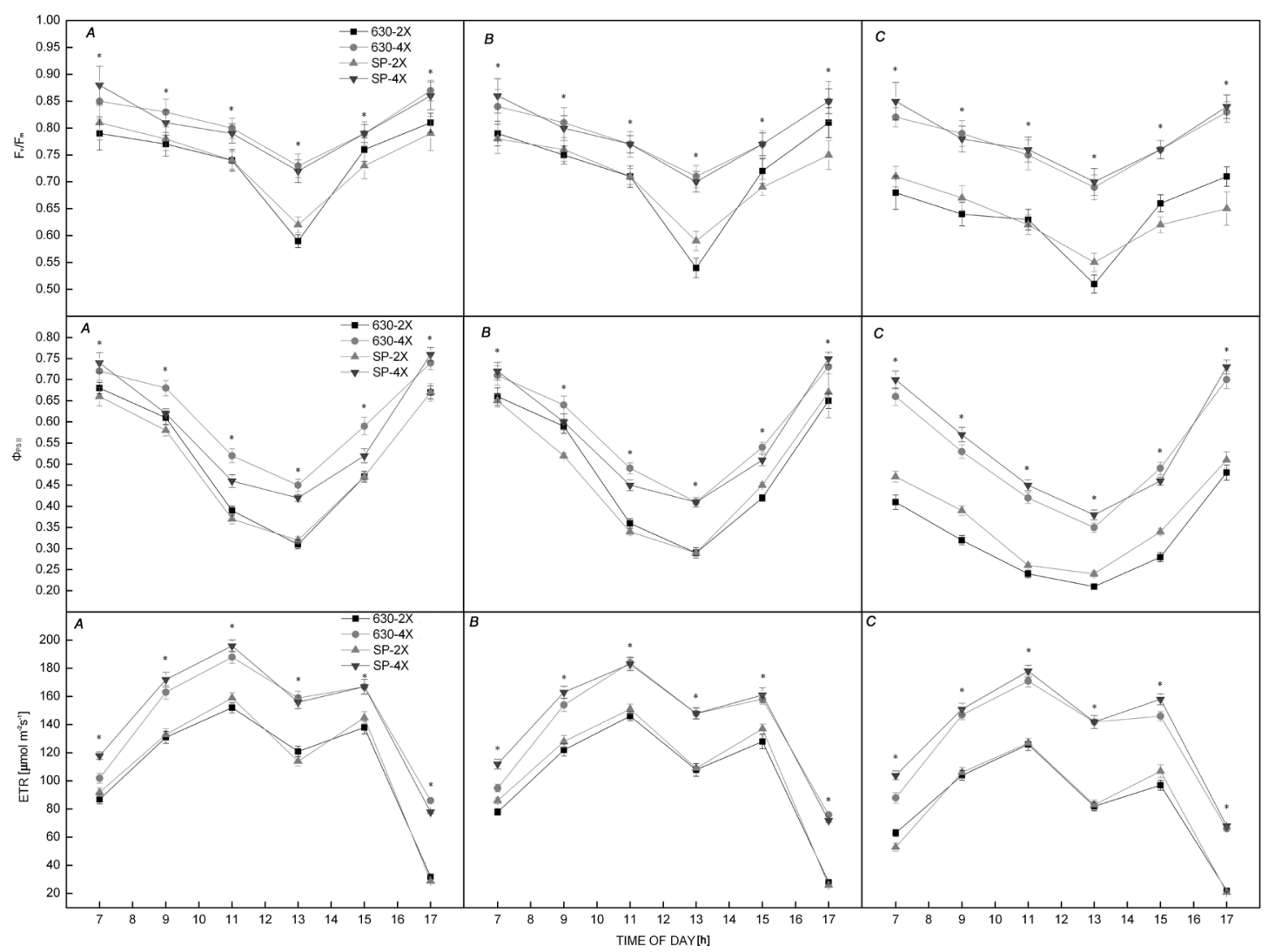

Fig. 4. Changes of chlorophyll fluorescence parameters in diploid and autotetraploid rice lines during the grain-filling stage: $15 \mathrm{~d}$ after anthesis $(A) ; 30 \mathrm{~d}$ after anthesis $(B)$; and $45 \mathrm{~d}$ after anthesis $(C)$. Error bars show SE, $n=10$. Asterisks indicate significant difference $(P<0.05)$ between two diploid rice lines and corresponding autotetraploid rice lines. $2 \mathrm{X}$ - diploid rice line, $4 \mathrm{X}$ - autotetraploid rice line, $\mathrm{F}_{\mathrm{v}} / \mathrm{F}_{\mathrm{m}}-$ maximum photochemical efficiency of PSII, $\Phi_{\mathrm{PSII}}-$ actual photochemical efficiency of photosystem II, ETR - electron transport rate.

because photosynthesis is the major metabolic pathway that converts carbon dioxide into organic compounds, such as fructose, glucose, sucrose, and starch in plants (Chang et al. 2017). Therefore, the plant's photosynthetic efficiency and conversion capacity of photoassimilates after anthesis have become important factors for crop starch accumulation (Miralles and Slafer 2007). Polyploidization can improve photosyntheticcharacteristics, enzymaticactivity, secondary metabolites, etc., in many plants (Meng et al. 2014, Ghimire et al. 2016, Liao et al. 2016, Wang et al. 2016). In autotetraploid plant, the basic genetic material remains the same, but gene dosage is multiplied. Hence autotetraploid plant has four sets of chromosomes, carries up four alleles, many genes duplicated by polyploidy retain their original function, and there is potential to enhance trait expression (Wendel 2000), e.g., improved photosynthetic characteristics have been reported in tetraploid black locust, triploid rice, etc. (Meng et al. 2014, Ghimire et al. 2016, Wang et al. 2016), the enzyme activity of potato granule-bound starch synthase is linearly correlated with dosage of allele (Flipse et al. 1996), the production of secondary metabolites displayed increased abundances in some polyploidy plants (Dhawan and Lavania 1996, Lavania 2005), significant upregulation of several key enzymes related to artemisinin biosynthetic pathway was observed in autotetraploid plants of Artemisia annua (Lin et al. 2011), and Ghotbi Ravandi et al. (2013) reported the tetraploid plants of Cichorium intybus with a significant increase in total phenolic compounds and chlorogenic acid content in leaves. Furthermore, genes associated with photosynthesis and enzyme activities were found to be upregulated in the autotetraploid vs. diploid comparison (Fan et al. 2015, Madani et al. 2015). These reports indicated the most duplicate genes retained original functions, and enhanced trait expression in polyploid plants. In our experiments, Chl content, $P_{\mathrm{N}}, \mathrm{ETR}, \mathrm{F}_{\mathrm{v}} / \mathrm{F}_{\mathrm{m}}$, and $\Phi_{\text {PSII }}$ were found to be upregulated in autotetraploid rice lines compared to diploid lines during the grainfilling stage, suggesting that photosynthetic capacity and photosynthetic efficiency were accelerated by increasing of the ploidy level, which would ensure sufficient photoassimilates for autotetraploid rice lines to synthesize starch. These advantages were especially obvious at the late stage of grain-filling process. Photorespiration is an inherent feature of plants. It is estimated that about $1 / 3$ of carbon dioxide assimilation in photosynthesis is released by photorespiration (Bauwe et al. 2010). Photorespiration consumes photosynthesis products, resulting in a reduced production. The most interesting finding was that chromosome doubling reduced the photorespiration of 

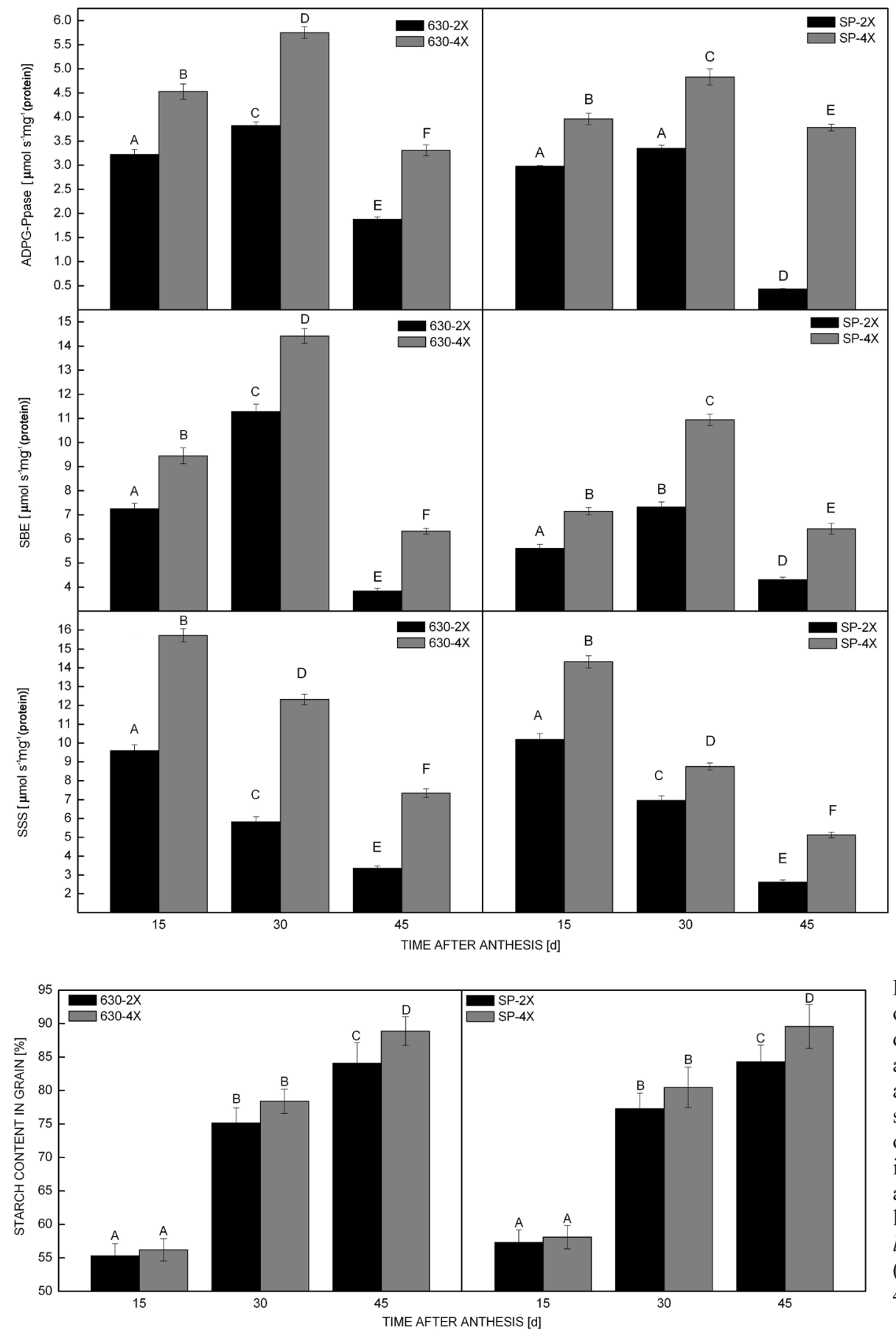

Fig. 5. The activities of ADP-glucose pyrophosphorylase (ADPG-Ppase), soluble starch synthase (SSS), and starch-branching enzyme (SBE) in grains of diploid and autotetraploid rice during the grain-filling stage. Error bars show SE, $n=3$. Oneway analysis of variance $(A N O V A)$ was used to indentify differences between diploid and corresponding autotetraploid rice line in each treatment. Values with different letters are significantly different $(P<0.05) .2 X-$ diploid rice line, $4 \mathrm{X}$ - autotetraploid rice line.

Fig. 6. Starch accumulation in grains of diploid and autotetraploid rice lines during the grain-filling stage: $15 \mathrm{~d}$ after anthesis $(A) ; 30 \mathrm{~d}$ after anthesis $(B)$; and $45 \mathrm{~d}$ after anthesis $(C)$. Error bars show $\mathrm{SE}, n=3$. One-way analysis of variance (ANOVA) was used to indentify differences between diploid and corresponding autotetraploid rice lines in each time. Values with different letters are significantly different $(P<0.05) .2 X-$ diploid rice line, $4 \mathrm{X}$ - autotetraploid rice line. rice. The two autotetraploid rice lines maintained lower $P_{\mathrm{R}}$ than the corresponding diploid rice lines during the grainfilling stage. During the grain-filling stage, autotetraploid rice lines maintained higher photosynthetic capacity and efficiency of light energy utilization, lower consumption of photosynthesis products than corresponding diploid lines, which could be beneficial to promote amount of photoassimilates in autotetraploid rice lines.

Starch biosynthesis in rice endosperm catalyzed by a series of enzymes can assimilate photoassimilates into starch. ADPG-Ppase, SSS, and SBE are key enzymes involved in controlling starch synthesis and accumulation (Myers et al. 2000, Pandey et al. 2012). ADPG-Ppase is the first rate-limiting enzyme in the process of starch synthesis (MacLeod and Duffus 1988, Jenner 1991, Kato 1995, Jiang et al. 2003). ADPG-Ppase catalyzes the synthesis of ADPG, which is the glucose donor in starch synthesis in rice. The activity of ADPG-Ppase in grains of autotetraploid rice line was greater than that in corresponding diploid rice line, indicating that more ADPG could be generated by autotetraploid rice line, which resulted in an increased supply of the ADP-glucose donor for starch synthesis 
during the grain-filling stage. The glucose molecule of ADPG is transferred to the nonreducing ends of the $\alpha-1,4$-glucan chain by SSS to form amylose. SSS promotes the formation of $\alpha-1,4$-glycosidic bonds in the amylopectin molecules of starch particles (Larkin et al. 2003, Butardo et al. 2011). The formation of branches between $\alpha-1,6$-glycosidic bonds in amylopectin is catalyzed by SBE. It promoted the enlargement of dextran molecules, meanwhile, it was favorable to the catalyzed reaction of ADPG-Ppase and SSS, so that more starch could be catalyzed and synthesized in a short time (Nakamura et al. 2010). The activities of ADPG-Ppase, SSS, and SBE in grains of autotetraploid rice lines were significantly higher than that in corresponding diploid rice lines during the grain-filling stage, the conversion of photoassimilates to starch was accelerated by increasing of enzyme activity related to starch accumulation in autotetraploid rice lines. It was suggested that the improved starch content in autotetraploid mainly is attributed to the increased photosynthetic capacity, photosynthetic electron transfer efficiency, and enzyme activity related to starch synthesis in the autotetraploid. After maturation, the 1000-grain masses of $630-4 \mathrm{X}$ and SP-4X was 50.8 and $53.1 \mathrm{~g}$, respectively. Moreover, the 630-2X and SP-2X had 1000-grain masses that were 29.2 and $25.1 \mathrm{~g}$, respectively (Yang et al. 2013). The kernel masses of two autotetraploid rice lines were significantly higher compared to those of corresponding diploid rice lines.

In conclusion, autotetraploid rice lines maintained higher Chl content, $P_{\mathrm{N}}, \mathrm{ETR}, \mathrm{F}_{\mathrm{v}} / \mathrm{F}_{\mathrm{m}}$, and $\Phi_{\mathrm{PSII}}$ and lower $P_{\mathrm{R}}$ than that of the corresponding diploid lines during the grainfilling stage. These advantages increased photosynthetic capacity and utilization efficiency of light energy and reduced consumption of photosynthate products. This, in turn, accelerated photosynthate assimilation, increased amount of photosynthates to meet the needs of starch synthesis. On the other hand, the activities of ADPG-Ppase, $\mathrm{SSS}$, and SBE in grains of autotetraploid rice lines were higher than that in corresponding diploid rice lines. The higher ADPG-Ppase, SSS, and SBE activity was beneficial for converting photosynthetic products into starch. Therefore, autotetraploid rice line had a higher capacity for starch synthesis than the corresponding diploid rice line. It was the reason why the starch content in grains of autotetraploid rice lines was higher than that of diploid rice lines.

\section{References}

Arnon D.I.: Copper enzymes in isolated chloroplasts. Polyphenoloxidase in Beta vulgaris. - Plant Physiol. 24: 1-15, 1949.

Asaoka M., Okuno K., Sugimoto Y., Fuwa H.: Developmental changes in the structure of endosperm starch of rice (Oryza sativa L.). - Agr. Biol. Chem. Tokyo 49: 1973-1978, 1985.

Awika J.M.: Major cereal grains production and use around the world. - In: Awika J.M., Piironen V., Bean S. (ed.): Advances in Cereal Science: Implications to Food Processing and Health Promotion. Pp. 1-13. American Chemical Society, Washington 2011.

Baker N.R.: Chlorophyll fluorescence: A probe of photosynthesis in vivo. - Annu. Rev. Plant Biol. 59: 89-113, 2008.
Ball S.G., van de Wal M.H.B.J., Visser R.G.F.: Progress in understanding the biosynthesis of amylose. - Trends Plant Sci. 3: 462-467, 1998.

Bauwe H., Hagemann M., Fernie A.R.: Photorespiration: players, partners and origin. - Trends Plant Sci. 15: 330-336, 2010.

Birchler J.A., Auger D.L., Riddle N.C.: In search of the molecular basis of heterosis. - Plant Cell 15: 2236-2239, 2003.

Butardo V.M., Fitzgerald M.A., Bird A.R. et al.: Impact of downregulation of starch branching enzyme IIb in rice by artificial microRNA- and hairpin RNA-mediated RNA silencing. J. Exp. Bot. 62: 4927-4941, 2011.

Chang H., Huang H.E., Cheng C.F. et al.: Constitutive expression of a plant ferredoxin-like protein ( $\mathrm{pflp}$ ) enhances capacity of photosynthetic carbon assimilation in rice (Oryza sativa). Transgenic Res. 26: 279-289, 2017.

Dhawan O.P., Lavania U.C.: Enhancing the productivity of secondary metabolites via induced polyploidy: a review. Euphytica 87: 81-89, 1996.

Fan G., Wang L., Deng M. et al.: Transcriptome analysis of the variations between autotetraploid Paulownia tomentosa and its diploid using high-throughput sequencing. - Mol. Genet. Genomics 290: 1627-1638, 2015.

Flipse E., Keetels C.J., Jacobsen E., Visser R.G.: The dosage effect of the wild-type GBSS allele is linear for GBSS activity but not for amylose content: absence of amylose has a distinct influence on the physico-chemical properties of starch. Theor. Appl. Genet. 92: 121-127, 1996.

Fujita N., Kubo A., Suh D.S. et al.: Antisense inhibition of isoamylase alters the structure of amylopectin and the physicochemical properties of starch in rice endosperm. Plant Cell Physiol. 44: 607-618, 2003.

Ghimire B.K., Seong E.S., Nguyen T.X. et al.: Assessment of morphological and phytochemical attributes in triploid and hexaploid plants of the bioenergy crop Miscanthus $\times$ giganteus. - Ind. Crop Prod. 89: 231-243, 2016.

Ghotbi Ravandi E., Rezanejad F., Zolala J., Dehghan E.: The effects of chromosome-doubling on selected morphological and phytochemical characteristics of Cichorium intybus L. J. Hortic. Sci. Biotech. 88: 701-709, 2013.

Guan X.Q., Zhao S.J., Li D.Q., Shu H.R.: Photoprotective functions of photorespiration in several grapevine cultivars under drought stress. - Photosynthetica 42: 31-36, 2004.

Han X.Z., Hamaker B.R.: Amylopectin fine structure and rice starch paste breakdown. - J. Cereal Sci. 34: 279-284, 2001.

He Y.C., Ge J., Wei Q. et al.: Using a polyploid meiosis stability (PMeS) line as a parent improves embryo development and the seed set rate of a tetraploid rice hybrid. - Can. J. Plant Sci. 91: 325-335, 2011.

Hegarty M.J., Hiscock S.J.: Genomic clues to the evolutionary success of polyploid plants. - Curr. Biol. 18: R435-R444, 2008.

James M.G., Denyer K., Myers A.M.: Starch synthesis in the cereal endosperm. - Curr. Opin. Plant Biol. 6: 215-222, 2003.

Jenner C.F.: Effects of exposure of wheat ears to high temperature on dry matter accumulation and carbohydrate metabolism in the grain of two cultivars. I. Immediate response. - Aust. J. Plant Physiol. 18: 165-177, 1991.

Jeon J.S., Ryoo N., Hahn T.R. et al.: Starch biosynthesis in cereal endosperm. - Plant Physiol. Bioch. 48: 383-392, 2010.

Jiang D., Cao W.X., Dai T.B., Jing Q.: Activities of key enzymes for starch synthesis in relation to growth of superior and inferior grains on winter wheat (Triticum aestivum L.) spike. Plant Growth Regul. 41: 247-257, 2003.

Kato T.: Change of sucrose synthase activity in developing endosperm of rice cultivars. - Crop Sci. 35: 827-831, 1995.

Larkin P.D., McClung A.M., Ayres N.M., Park W.D.: The 
effect of the Waxy locus (Granule Bound Starch Synthase) on pasting curve characteristics in specialty rices (Oryza sativa L.). - Euphytica 131: 243-253, 2003.

Lavania U.: Genomic and ploidy manipulation for enhanced production of phyto-pharmaceuticals. - Acta Hortic. 3: 170-177, 2005.

Liao T., Cheng S., Zhu X. et al.: Effects of triploid status on growth, photosynthesis, and leaf area in Populus. - Trees 30: $1-11,2016$.

Lin X., Zhou Y., Zhang J. et al.: Enhancement of artemisinin content in tetraploid Artemisia annua plants by modulating the expression of genes in artemisinin biosynthetic pathway. Biotechnol. Appl. Bioc. 58: 50-57, 2011.

MacLeod L.C., Duffus C.M.: Reduced starch content and sucrose synthase activity in developing endosperm of barley plants grown at elevated temperatures. - Aust. J. Plant Physiol. 15: 367-375, 1988.

Madani H., Hosseini B., Dehghan E., Rezaei-Chiyaneh E.: Enhanced production of scopolamine in induced autotetraploid plants of Hyoscyamus reticulatus L. - Acta Physiol. Plant. 37: 55, 2015.

Meng F., Peng M., Pang H., Huang F.: Comparison of photosynthesis and leaf ultrastructure on two black locust (Robinia pseudoacacia L.). - Biochem. Syst. Ecol. 55: 170-175, 2014.

Miralles D.J., Slafer G.A.: Sink limitations to yield in wheat: how could it be reduced? - J. Agr. Sci.-Cambridge 145: 139-149, 2007.

Myers A.M., Morell M.K., James M.G., Ball S.G.: Recent progress toward understanding biosynthesis of the amylopectin crystal.Plant Physiol. 122: 989-997, 2000.

Nakamura Y., Utsumi Y., Sawada T. et al.: Characterization of the reactions of starch branching enzymes from rice endosperm. Plant Cell Physiol. 51: 776-794, 2010.

Nakamura Y., Yuki K., Park S.Y., Ohya T.: Carbohydrate metabolism in the developing endosperm of rice grain quality. Plant Cell Physiol. 30: 833-839, 1989.

Nakamura Y., Yuki K.: Changes in enzyme activities associated with carbohydrate metabolism during the development of rice endosperm. - Plant Sci. 82: 15-20, 1992.

Otto S.P., Whitton J.: Polyploid incidence and evolution. - Annu. Rev. Genet. 34: 401-437, 2000.

Pandey M.K., Rani N.S., Madhav M.S. et al.: Different isoforms of starch-synthesizing enzymes controlling amylose and amylopectin content in rice (Oryza sativa L.). - Biotechnol. Adv. 30: 1697-1706, 2012.

Reddy K.R., Subramanian R., Zakiuddin S.A., Bhattacharya K.R.: Viscoelastic properties of rice flour pastes and their relationship to amylose content and rice quality. - Cereal Chem. 71: 548-552, 1994.

Reynolds M., Foulkes J., Furbank R. et al.: Achieving yield gains in wheat. - Plant Cell Environ. 35: 1799-1823, 2012.

Rieseberg L.H., Willis J.H.: Plant speciation. - Science 317: 910-914, 2007.

Swaminathan M.S.: Can science and technology feed the world in 2025? - Field Crop. Res. 104: 3-9, 2007.

Tu S.B., Luan L., Liu Y.H. et al.: Production and heterosis analysis of rice autotetraploid hybrids. - Crop Sci. 47: 2356-2363, 2007.

Tuncel A., Okita T.W.: Improving starch yield in cereals by overexpression of ADPglucose pyrophosphorylase: expectations and unanticipated outcomes. - Plant Sci. 211: 52-60, 2013.

Vandepoele K., Simillion C. and Peer Y.V.D.: Evidence that rice and other cereals are ancient aneuploids. - Plant Cell 15: 2192-2202, 2003.

Wang B.S., Ma M.Y., Lu H.G. et al.: Photosynthesis, sucrose metabolism, and starch accumulation in two NILs of winter wheat. - Photosynth. Res. 126: 363-373, 2015.

Wang S., Chen W., Yang C. et al.: Comparative proteomic analysis reveals alterations in development and photosynthesis-related proteins in diploid and triploid rice. - BMC Plant Biol. 16: 199, 2016.

Wendel J.F.: Genome evolution in polyploids. - Plant Mol. Biol. 42: 225-249, 2000.

Xie L.Y., Lin E.D., Zhao H.L., Feng Y.X.: Changes in the activities of starch metabolism enzymes in rice grains in response to elevated $\mathrm{CO}_{2}$ concentration. - Int. J. Biometeorol. 60: 727-736, 2016.

Yang P.M., Huang Q.C., Qin G.Y. et al.: Different drought stress responses in photosynthesis and reactive oxygen metabolism between autotetraploid and diploid rice. - Photosynthetica 52: 193-202, 2014.

Yang P.M., Huang Q.C., Qin G.Y., Zhao S.P.: Different responses to $\mathrm{N}^{+}$beam implantation between diploid and autotetraploid rice. - Appl. Biochem. Biotech. 170: 552-561, 2013.

(C) The authors. This is an open access article distributed under the terms of the Creative Commons BY-NC-ND Licence. 